\title{
The Cooling Power of the Air in Trains, Trams, and Buses.
}

By Leonard HILL, F.R.S., with the co-operation of M. BRAD (from the National Institute for Medical Research).

TH

$\mathrm{HE}$ body resembles a motor-car engine in that it is producing heat by the combustion, not of petrol but of food, and, just as the car has a radiator, so has the body-namely, the skin-in order to lose heat and keep at body temperature, that is, the temperature at which the living tissues have to live. During muscular exercise, about four times as much heat is produced as work, and when hard exercise is taken, such as climbing, the heat production of the body may be five times as great as when sitting at rest. The loss of heat is controlled, just as the production, by bodily mechanisms. To accelerate heat loss, the skin flushes with blood and perspires ; clothes are thrown off and the body fanned. Over-warm stagnant atmospheres and over-clothing check the production of body heat and lead to disinclination to exertion, loss of appetite, and, in time, to debility. Cool surroundings and light clothing, on the other hand, increase the production of body heat, tone up the body, stimulate appetite, impel to activity, and generally improve health.

The ordinary thermometer indicates the average effect of the temperature of the surroundings on itself. Unlike the body it does not produce heat. If a fan is set to blow about the air of the room in which it hangs, its reading does not alter. The body, on the other hand, is very effectually cooled by the fan. The thermometer is, then, an untrustworthy guide to ventilation. The kata-thermometer has been introduced to remedy its defects. This instrument has a bulb which is warmed to just above the average temperature of the human skin, and its rate of cooling is measured during a drop of five degrees, namely, between $100^{\circ}$ and $95^{\circ} \mathrm{F}$.

In this way the power of the air in any locality to cool a surface approximately at skin temperature can be measured. The measurements are made in millicalories per sq. $\mathrm{cm}$. per second. The bulb of the instrument is roughly the size of the end joint of the thumb. The big masses of the body are cooled less rapidly, having a smaller surface in proportion to their bulk. The kata-thermometer does not, then, actually measure the cooling effect of the air on the human body, but is a valuable indicator of comfortable and healthy conditions.

In rooms kept fresh and warm enough for sedentary work, the cooling power is found to be about 6 . In stuffy rooms 4 , or even less; in rooms rather cold for comfort, 8. Out-of-doors, where the wind blows, cooling powers are higher; for example, ro on a genial summer day, 20 on mild winter days, 40 on cold winter days. The open-air worker is stimulated by much higher cooling powers than the sedentary workers, even when the temperature is the same indoors and out, owing to the movement of the air out-of-doors.

As we have said, an adequate cooling power of the air is required to keep " the fire of life " from burning too feebly, to tone up the muscles, invigorate the nervous system, and make keen the appetite and efficient the digestion and action of the bowels.
It has been shown that exposure of the naked body of children to sun and open air, with of course wise prevention of over-cooling, has a wonderful curative effect on states of debility, rickets, and surgical tuberculosis. An adequate increase of cooling power puts up the basal metabolism, that is the heat production of the resting body, even 50-Ioo per cent. We know that thousands of clerks, shop assistants, factory hands taken from lives spent in monotonous over-warm places, were changed from feebly developed, nervous, dyspeptic men into strong healthy soldiers by training in open-air exercises during the Great War.

Severely exposed to weather in the trenches, these men suffered far less from catarrhal diseases than those who continued in employment in cities. The soldiers caught " colds " not in the trenches, but when on leave and infected by close contact with "carriers" in the crowded places of cities. Americans overheat their houses and suffer from catarrhal complaints. The death-rate from pneumonia in U.S.A. has not gone down with that progress in medicine which has notably lowered the death-rates from most other diseases. While exposure to the open air, with the invigorating effect of cool winds and daily exercise, is necessary for all who want to attain full health and enjoyment of life, people, mistakenly attributing the origin of catarrhal disease to exposure to cold, have in the past demanded the over-heating of railway carriages and shutting of windows and the closing in of the roof-seats of trams. Suggestions recently have been put forward for the heating of trams, and the roofing over of the outside seats of buses has been discussed. There have been many who have wished, and some more courageous, who have struggled to secure the opening of windows in trains, and these last have been ridiculed in the Press as " open-air fiends" by journalists who are habituated to the stuffy over-warm newspaper offices of Fleet Street. Soldiers, however, hardened in the trenches, on returning from the Great War demanded greater opening of windows in trains, and this habit of open windows has of late become more general.

People are beginning to realise that catarrhal infections are spread by wrong conditions of the atmosphere indoors, and by repeated massive doses of microbes inhaled from "carriers" who sneeze and cough in close crowded places. Even comic artists and artists of patent medicine advertisements now try to illustrate the happenings of such infection. As tube trains and trams are closed up more than buses, and as people continue to dispute over the opening of windows in steam trains, it seemed worth while measuring the cooling powers of the air by means of the kata-thermometer in such trains with windows shut or open, and in tube trains, trams, and buses, comparing in these last the inside and outside. The temperature of the air was also taken and the velocity of the air movement calculated from a formula which allows the kata-thermometer to be used as a very sensitive anemometer. The following are the average results of observations made when conditions were best in the non-crowded 
parts of the day, in mild or cool weather, during September and October of r923.

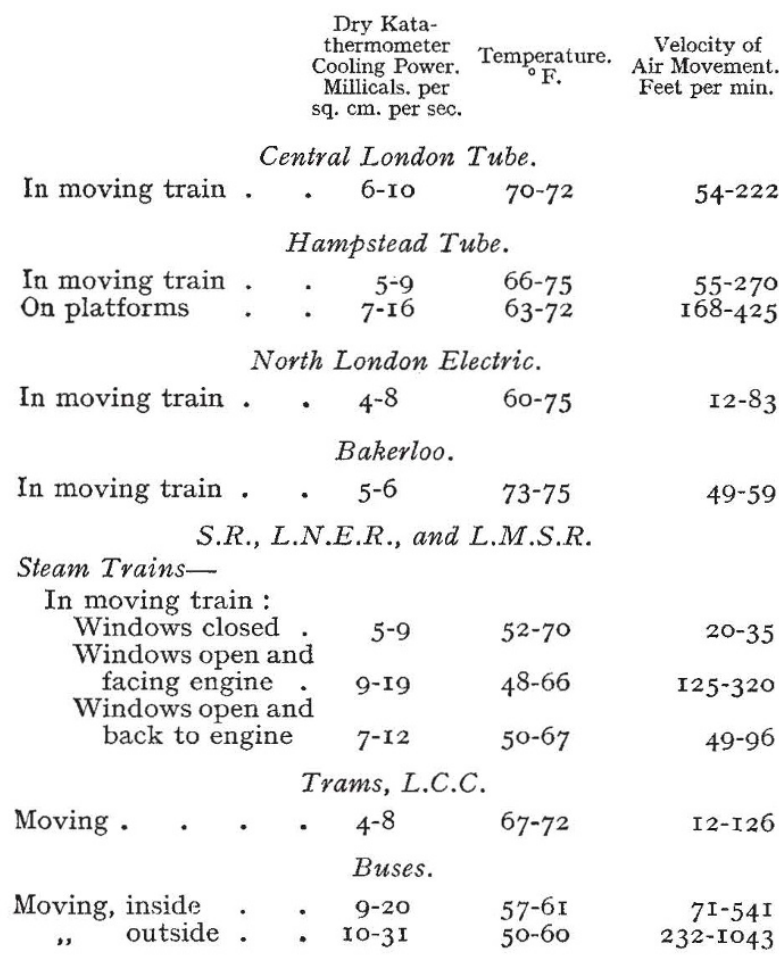

The standard dry kata-thermometer cooling power suitable for sedentary work in ordinary clothing is 6 .
Lower cooling powers produce stuffy sensations and require less clothing. If people used foot-warmers, and in some cases wore more clothing when at sedentary work, they could easily bear windows open and a cooling power of 8 , or even ro, and have the great advantage of breathing cooler, cleaner air. A sanatorium ward is best kept at such a cooling power as ro. In travelling to and fro wearing outdoor wraps, people can, with advantage, be stimulated by wind giving much higher cooling powers than 6 . The bus stands pre-eminent in this respect, and healthy people who enjoy a blow in the fresh air and recognise the good effect of this on health rejoice in the open roof-seats of the bus. The cooling powers outside the bus were ro-3r against 4-8 in the tram. It is regrettable that the roof-seats of trams were ever closed. Those of buses certainly should not be. A removable rain screen open at the sides is all that is wanted in bad weather.

Tubes and steam trains with closed windows and trams are relatively stuffy places, cooling powers 4-1o, compared to outside of buses, cooling powers I0-3I, and steam trains with windows open, cooling powers 9-I9. The seat facing the engine in the steam train with window open is recognised to be much cooler than that with the back to the engine; by how much on cool autumnal days the figures show, 7-I2 against 9-I9. The cooling power at a seat facing the engine can be doubled or even trebled by opening the window.

The figures also show that movement of air and not temperature is the chief factor at work.

In steam trains with windows open and on the outside of buses, massive infection with the microbes from "carriers" is impossible.

\section{The British Association at Toronto.} (FROM OUR CORRESPONDENT.)

Toronto, August Io.

$\mathrm{O}^{\mathrm{s}}$ PPRESSIVELY hot weather during the first half of this year's meeting of the British Association at the University of Toronto has made the excursions into the neighbouring countryside particularly popular among the 2600 men of science and citizens who have enrolled as members to the present date. Thunder showers at night have, however, cooled down the hot lecture rooms and rendezvous periodically, and have thus made meetings possible without interfering with communication in the daytime between the score of University buildings utilised for them. The overseas party, numbering 573, was fêted on the way through eastern cities, and most members of it have been given hospitality in private houses in Toronto. Others, with more than three hundred men of science from the United States, are quartered in Unjversity residences. Hart House, which is the social and recreational centre of the, male University life, has been thrown open to men and women, and the dining-room has been extended to seat six hundred. The Toronto Board of Trade has been responsible for the enrolment of more than one thousand citizens, and the balance of local members is drawn from adjacent towns, many coming in every day for the meeting, so that the hotels are full.

The Convocation Hall of the University of Toronto, seating eighteen hundred people, was packed on Wednesday night, August 6, when Sir Ernest Rutherford vacated the president's chair for his successor, Sir David Bruce. While lightning flashed across black skies outside the building, Sir Robert Falconer, president of the University, welcomed the visitors and said that Canada needed the stimulus which this visit of the British Association would afford. Prof. J. C. Fields, president of the Royal Canadian Institute, also expressed the welcome of the hosts in the name of the Institute. Prof. J. C. McLennan, chairman of the general and executive committees, moved the vote of thanks to Sir David Bruce for his address.

Representative overseas delegates were received by Cabinet ministers in the Parliament Buildings on Wednesday afternoon, August 6, when the Hon. George H. Henry, senior Government minister, extended the hospitality of the Province to the Association. Sir Ernest Rutherford replied on behalf of the delegates. On the evening of August 7, a reception was given by the trustees and directors of the Royal Ontario Museum of Archeology, and was attended by two thousand people, including nearly all the members of the overseas party. The guests were received by Mr. J. B. O'Brian, the Hon. Charles McCrea, the Hon. Dr. Cody, and Mrs. Cody. Many social events have been held, including luncheons, teas, dinners, etc., arranged by No. 2859 , vOL. I 14$]$ 